Т. 1. Л.: Изд-во Ленинградского университета, 1983. $480 \mathrm{c}$.

22. Волковская-Курдюкова Е.А., Курдюков А.Б. Материалы по экологии и населению сов Приханкайской низменности // Русский орнитологический журнал. 2010. Т. 19, экспресс-выпуск 595. С. 1591-1612.

23. Кулаева Т.М. Отряд Совообразные Strigiformes // Птицы Волжско-Камского края. М.: Наука, 1977. C. 239-257.

24. Коровин В.А. Птицы в агроландшафтах Урала. Екатеринбург: Изд-во Уральского университета, 2004. $504 \mathrm{c}$.

25. Доржиев Ц.З., Дурнев Ю.А., Сонина М.В., Елаев Э.Н. Птицы Восточного Саяна. Улан-Удэ: Изд-во Бурятского ун-та, 2019. 400 с.
26. Доржиев Ц.З., Доржиева В.Д. К биологии размножения полевого воробья в Западном Забайкалье // Влияние антропогенных факторов на структуру и функционирование биоценозов. М.: Изд-во МГПИ, 1983. С. $78-88$.

27. Доржиев Ц.З., Доржиева В.Д. Особенности гнездования полевого воробья в населенных пунктах Забайкалья // Фауна и экология наземных позвоночных животных на территориях с разной степенью антропогенного воздействия. М.: Изд-во МГПИ, 1985. C. 21-34.

28. Полевой воробей Passer montanus L. (Характеристика вида на пространстве ареала) / под ред. Г.А. Носкова. Л.: Изд-во Ленинградского университета, 1981. $304 \mathrm{c}$.

\title{
USE OF CORVIDS' NESTS BY OTHER BIRD SPECIES IN BAIKAL SIBERIA AND MONGOLIA
} (C) 2019

Dorzhiev Tsydypzhap Zayatuevich, doctor of biological sciences, professor of Zoology and Ecology Department Badmaeva Evgeniya Nikolaevna, candidate of biological sciences, associate professor of Zoology and Ecology Department

Dayanzhav Tsogtbaatar, postgraduate student of Zoology and Ecology Department

Enkhsaikhan Uuganbayar, postgraduate student of Zoology and Ecology Department Buryat State University named after D. Banzarov (Ulan-Ude, Russian Federation)

Saaya Ariyana Tomur-oolovna, postgraduate student of Zoology and Ecology Department; junior researcher of Natural Sciences Laboratory

Buryat State University named after D. Banzarov (Ulan-Ude, Russian Federation); Tuvan Scientific Center (Kyzyl, Russian Federation)

Abstract. The paper presents the species composition of corvids in Baikal Siberia and Mongolia. More than 700 nests of 8 species of corvids in Transbaikalia, Baikal and Mongolia were examined. 133 cases of using nests of 5 species of corvids (Magpies, Eastern Carrion Crow, Rooks and Daurian Jackdaws) by other species of birds were noted. Nests of small corvids do not attract other birds. Nests of magpies are most commonly used; they are characterized by a specific structure. Of the 8 species that use corvid nests for nesting, Amur red-footed Falcon and longeared owl are obligate tenants. Then goes Kestrel that prefers magpie nests. The number of these types in many places is determined by the abundance of magpies and crows. In recent years, due to the high number of magpies, the number of Amur falcons in the region is growing. They began following magpies to penetrate the outskirts of UlanUde. Three species (Mallard, hobby, tree sparrows) are considered optional to be the tenants and three other species (Ruddy Shelduck, Long-eared Owl and House Sparrow) are considered to be random. Tree sparrows often nest in the magpie nests in natural habitats. Almost all types of tenants use old nests of the owners. Regional features in the use of corvid nests are revealed. Some species in different regions do not prefer the same nests of different types of corvids.

Keywords: nested relations; obligatory tenant; optional tenant; number; nests of corvids; Common Magpie; Eastern Carrion Crow; Raven; Rook; Daurian Jackdaw; Ruddy Shelduck; Mallard; Kestrel; Hobby; Amur Falcon; Ural Owl; Long-eared Owl; House Sparrow; Tree Sparrow; Transbaikalia; Baikal; Mongolia.

$* * *$

\section{ВЛИЯНИЕ ФЕНОЛОГИЧЕСКИХ ФАКТОРОВ НА МОРФОМЕТРИЧЕСКИЕ ПАРАМЕТРЫ СОЦВЕТИЙ РОДА CRATAEGUS L. В УСЛОВИЯХ КОЛЬСКОЙ СУБАРКТИКИ}

(C) 2019

Зотова Олеся Евгеньевна, младший научный сотрудник

лаборатории интродукции и акклиматизации растений

Гончарова Оксана Александровна, кандидат биологических наук, старший научный сотрудник лаборатории интродукции и акклиматизации растений

Полярно-альпийский ботанический сад-институт им. Н.А. Аврорина Кольского научного иентра РАН (2. Апатиты, Мурманская область, Российская Федерация)

Аннотация. В данной работе представлен материал о фенологическом развитии семи интродуцированных видах рода Crataegus L. в условиях Кольского Севера. Изученные виды боярышника характеризуются ранним началом вегетации, короткой длительностью линейного роста побегов и коротким периодом вегетации. 
Своевременное завершение процессов роста и одревеснения побегов способствуют успешной адаптации растений Crataegus в условиях интродукции. Изучены морфометрические показатели (количество цветков в соцветии, диаметр цветков, диаметр и плотность соцветия), характеризующие декоративные качества цветков и соцветий. Выделены виды Crataegus наиболее декоративные во время цветения. Растения изученных боярышников характеризуются средней продолжительностью префлорального периода, ежегодным / нерегулярным цветением. C. maximoviczii и $C$. dahurica имеют наиболее крупные цветки и соцветия. Эти виды имеют наибольшую декоративность во время цветения. Наиболее плотные соцветия характерны для видов с большим количеством цветков. Виды с более крупными цветками образуют более крупные соцветия и наоборот. В условиях Кольской Субарктики в основном от видовых особенностей зависит количество цветков в соцветии. C. maximoviczii рекомендован для использования в озеленении северных городов.

Ключевые слова: экологические факторы; экологические условия; фенологическое развитие; продолжительность вегетации; фенологические фазы; префлоральный период; интродукция; цветение; древесные растения; семейство Rosaceae Juss. - Розоцветные; род Crataegus L. - боярышник; количество цветков; соцветия; размер соцветий; плотность соцветий; Кольская Субарктика.

\section{Введение}

Участком проведения исследования является Полярно-альпийский ботанический сад-институт Кольского научного центра Российской академии наук (ПАБСИ КНЦ РАН). Объектами изучения выбраны выращиваемые на экспериментальном участке ПАБСИ растения рода Crataegus L. (сем. Rosaceae Juss.).

Полярно-альпийский ботанический сад-институт РАН размещается в 120 км к северу от Полярного круга. Территория экспериментального участка ПАБСИ располагается в трех км на запад от г. Апатиты. Среднемесячная температура наиболее холодного месяца (январь) около $-13^{\circ} \mathrm{C}$, наиболее теплого (июль) $-+10^{\circ} \mathrm{C} \ldots+14^{\circ} \mathrm{C}$. Первые заморозки в воздухе отмечаются уже в августе, последние - в конце мая и июне. Безморозный период длится 50-70 дней. Переход через $+5^{\circ} \mathrm{C}$ среднесуточных температур наблюдается 31 мая. Наиболее обильные осадки отмечаются в летние и осенние месяцы, а наименьшее их количество - в весенние. Количество осадков по среднемноголетним данным составляет 500-600 мм/год. Устойчивый снежный покров держится от 180 до 200 дней, высота снежного покрова 60-80 см. Вегетационный период составляет 90-120 дней [1].

В коллекционных фондах древесных интродуцентов ПАБСИ к семейству Rosaceae относят порядка $30 \%$ образцов (17 родов, 113 видов, 12 внутривидовых таксонов и 8 гибридов). Всего 280 образцов. Коллекции родов Sorbus L., Spiraea L., Crataegus L., Rosa L. представлены наиболее полно [2, с. 108].

Растения рода Crataegus L. распространены на значительной территории северного полушария, произрастают в умеренных, реже субтропических зонах. Виды рода Crataegus весьма декоративны в периоды цветения и плодоношения, в связи с чем широко применяются в зеленом строительстве. Цветение наступает в 10-15 лет. Период цветения наблюдается после распускания листьев в конце мая - начале

таблица 1 - Исследуемые образцы Crataegus

\begin{tabular}{|l|c|l|c|}
\hline \multicolumn{1}{|c|}{ Вид } & $\begin{array}{c}\text { Год включения } \\
\text { в испытание }\end{array}$ & \multicolumn{1}{c|}{$\begin{array}{c}\text { Происхождение } \\
\text { первичного материала }\end{array}$} & Б3 \\
\hline Crataegus cuneata Siebold \& Zucc. & 1986 & ск Харьков & $1-2$ \\
\hline Crataegus dahurica Koehne ex C.K. Schneid. & 1979 & сд Хабаровский край & 1 \\
\hline Crataegus flabellata (Bosc ex Spach) K. Koch & 1998 & ск Санкт-Петербург & $1-2$ \\
\hline Crataegus russanovii Cinovskis & 1998 & ск Архангельск & $1-2$ \\
\hline Crataegus laevigata (Poir.) DC. & 1983 & сд Калининградская область & $1-2$ \\
\hline Crataegus maximoviczii C.K. Schneid. & 1998 & ск Архангельск & 1 \\
\hline Crataegus sanguinea Pall. & 1989 & сд р. Дянышка, Якутия & $1-2$ \\
\hline
\end{tabular}

Примечание. Ск / сд - семена культурного / природного происхождения, Б3 - балл зимостойкости. июня. Сложные щитковидные или зонтиковидные соцветия располагаются на коротких боковых побегах текущего года [3, с. 514-517].

По С.В. Мухаметовой и др. [4, с. 123; 5, с. 153], «морфометрические параметры цветков и соцветий являются важными признаками, характеризующими видовые особенности растений. У боярышников определяющими видовую принадлежность признаками являются количество тычинок и пестиков, окраска пыльников, опушение осей соцветий, цветоножек и гипантия, размеры венчика цветков, количество цветков в соцветии и т.д. В период цветения наиболее важными декоративными качествами растений боярышников являются количество и размеры соцветий, складывающихся из размеров отдельных цветков и их числа в соцветии».

В естественных растительных сообществах Мурманской области растения рода Crataegus не произрастают, но в культуре встречаются, при этом не требуют особого ухода.

Во многих ботанических садах созданы крупные коллекции боярышников, т.к. растения рода Crataegus отличаются значительным видовым и формовым разнообразием [6, с. 3]. Анализу результатов интродукции растений рода на северо-западе посвящен ряд работ [7; 8]. Некоторые результаты интродукции растений рода Crataegus в ПАБСИ представлены ранее [9-11].

\section{Цель и объекты исследования}

Цель: изучение фенологического развития и характеристика морфометрических параметров соцветий 7 интродуцированных видов рода Crataegus, выращиваемых в ПАБСИ КНЦ РАН (экспериментальный участок, г. Апатиты). Характеристика исследуемых образцов Crataegus L. представлена в таблице 1. Латинские названия растений в соответствии с ThePlantList.org и работой С.К. Черепанова [12; 13, c. $855-857]$. 
Зотова О.Е., Гончарова О.А.

Влияние фенологических факторов на морфометрические параметры соцветий рода Crataegus L.

Общая биология

Исследуемые растения имеют культурное и природное семенное происхождение. По возрастным категориям можно выделить две возрастные группы: 21-22 года и 29-39 лет.

\section{Материал и методы исследований}

При исследовании использовали следующие методики $[14 ; 15$, с. $22,61,65 ; 16]$. Эмпирические фенодаты были переведены в непрерывный числовой ряд $[17$, с. 264]. Для каждого параметра вычисляли статистические характеристики согласно общепринятым методикам [18-20]. Математическая обработка результатов проведена с использованием пакета данных программы Microsoft Excel.

Сбор морфометрических характеристик соцветий каждого образца выполнен в 2017 г. во время его обильного цветения. Соцветия отобраны произвольно в центральной зоне кроны с 3-5 экземпляров каждого вида в количестве 10 шт. У видов, содержащихся в одном экземпляре, измерено 30 соцветий. Диаметр соцветий и цветков измеряли по максимальной окружности линейкой с точностью до 0,1 см. Плотность соцветий вычисляли как отношение количества цветков в соцветии к его диаметру.

\section{Результаты и их обсуждение}

В таблице 2 представлены среднемноголетние сроки наступления фенологических фаз за 20012015 гг.: раскрытие вегетативных почек (Пч2), начало / окончание роста побегов (Пб1 / Пб2), одревеснение побегов (O2), осенняя окраска листьев (Л4), опадение листьев (Л5), начало / окончание цветения (Ц4 / Ц5); среднемноголетнюю продолжительность префлорального периода (ПФП), цветения (ПЦ), линейного роста побегов (РП), периода вегетации (ПВ).

Начало вегетации у растений рода Crataegus отмечается 15-26 мая, что соответствует ранним срокам начала вегетации. Исследуемые растения Crataegus отличаются короткой продолжительностью линейного роста побегов. Более ранние сроки начала и окончания вегетации, окончания роста и одревеснения побегов характерны для растений природного происхождения. Вегетация и рост побегов начинается в близкие временные сроки, отмечается наступление фенофаз у растений старшей и младшей возрастной группы. Ранними сроками окончания линейного роста и одревеснения побегов характеризуются рас- тения старшей возрастной группы, чем образцы 1819-летнего возраста. По срокам цветения можно выделить две группы. C.flabellata, C. maximoviczii, C. sanquinea отличаются более ранними сроками цветения по сравнению с образцами $C$. cuneata, C. laevigata, C. dahurica. В целом, для боярышников характерен префлоральный период средней продолжительности.

По П.И. Лапину, «морозостойкость древесных растений в ходе сезонного развития резко повышается в результате своевременного завершения роста и дифференциации органов во время перехода в состояние глубокого покоя» [21, с. 14]. Соответственно, для успешной перезимовки необходимо своевременное окончание роста и одревеснения побегов, появление осенней окраски листвы. Растения природного происхождения, старшей возрастной группы имеют адаптивными преимуществами.

Морфометрические характеристики соцветий интродуцированных растений рода Crataegus в условиях Кольской Субарктики отражены в таблице 3.

Рассмотрим морфометрические характеристики соцветий растений рода Crataegus в ПАБСИ. Наименьшая ширина соцветий отмечается у C. laevigata, максимальная - у C. maximoviczii. Средняя ширина соцветий у исследуемых растений составила 5,5 $\pm 0,50 \mathrm{~cm}$.

Характерно, что C. laevigata и C. maximoviczii обладали крайними значениями количества цветков в соцветии 9,9 и 27,6 шт. соответственно, среднее значение этого показателя составило 16,9 $\pm 2,9$ шт.

Минимальный диаметр цветков наблюдался у C. sanguinea (1,41 cм), максимальный - у C. maximoviczii u C. dahurica (1,74 см). Средняя ширина цветков у образцов Crataegus составила 1,6 $\pm 0,05$ см.

Самые плотные соцветия свойственны для $C$. $d a$ hurica (3,9 шт./см), для C. maximoviczii присущи менее плотные соцветия (3,9 шт./см), также эти виды отличались наибольшим количествов цветков. Наименьшее количество цветков в соцветии и наименьший диаметр цветков и соцветия свойственны для C. laevigata. Для этого же вида свойственны наименее плотные соцветия (2,3 шт./см). Плотность соцветий исследованных видов в среднем составила $3,01 \pm 0,25$ шт./cм.

Таблица 2 - Средние многолетние фенодаты интродуцированных растений рода Crataegus в ПАБСИ

\begin{tabular}{|l|c|c|c|c|c|c|c|c|c|c|c|}
\hline \multicolumn{1}{|c|}{ Вид } & Пч2 & Пб1 & Пб2 & О2 & Л4 & Л5 & Ц4 & Ц5 & ПФП / ПЦ, сут. & РП, сут. & ПВ, сут. \\
\hline C. cuneata & 20,5 & 7,6 & 10,7 & 2,8 & 11,9 & 1,10 & 1,7 & 10,7 & $42 / 9$ & 33 & 110 \\
\hline C. dahurica & 15,5 & 2,6 & 14,7 & 4,8 & 28,8 & 25,9 & 29,6 & 9,7 & $45 / 10$ & 42 & 105 \\
\hline C. flabellata & 18,5 & 30,5 & 23,7 & 12,8 & 31,8 & 25,9 & 22,6 & 30,6 & $35 / 8$ & 54 & 105 \\
\hline C. russanovii & 26,5 & 5,6 & 22,7 & 11,8 & 13,9 & 2,10 & - & - & - & 47 & 110 \\
\hline C. laevigata & 19,5 & 6,6 & 7,7 & 28,7 & 10,9 & 2,10 & 1,7 & 10,7 & $43 / 9$ & 31 & 114 \\
\hline C. maximoviczii & 18,5 & 30,5 & 20,7 & 6,8 & 3,9 & 1,10 & 24,6 & 1,7 & $37 / 7$ & 51 & 108 \\
\hline C. sanguinea & 12,5 & 31,5 & 5,7 & 19,7 & 23,8 & 16,9 & 23,6 & 1,7 & $42 / 8$ & 54 & 103 \\
\hline
\end{tabular}

Таблица 3 - Морфометрические особенности цветков и соцветий некоторых видов рода Crataegus в ПАБСИ

\begin{tabular}{|l|c|c|c|c|}
\hline \multicolumn{1}{|c|}{ Представитель } & $\begin{array}{c}\text { Диаметр соцветия, } \\
\text { см }\end{array}$ & $\begin{array}{c}\text { Диаметр цветка, } \\
\text { см }\end{array}$ & $\begin{array}{c}\text { Количество цветков } \\
\text { в соцветии, шт. }\end{array}$ & $\begin{array}{c}\text { Плотность соцветия, } \\
\text { шт./см }\end{array}$ \\
\hline C. cuneata & $4,6 \pm 0,18$ & $1,64 \pm 0,03$ & $11,0 \pm 0,66$ & $2,5 \pm 0,19$ \\
\hline C. dahurica & $6,9 \pm 0,20$ & $1,74 \pm 0,04$ & $26,6 \pm 1,70$ & $3,9 \pm 0,33$ \\
\hline C. flabellata & $4,9 \pm 0,19$ & $1,59 \pm 0,02$ & $12,7 \pm 0,48$ & $2,7 \pm 0,13$ \\
\hline C. russanovii & $5,01 \pm 0,23$ & $1,59 \pm 0,04$ & $13,7 \pm 0,87$ & $2,8 \pm 0,29$ \\
\hline C. laevigata & $4,5 \pm 0,16$ & $1,54 \pm 0,03$ & $9,9 \pm 0,44$ & $2,3 \pm 0,15$ \\
\hline C. maximoviczii & $7,6 \pm 0,21$ & $1,74 \pm 0,03$ & $27,6 \pm 1,26$ & $3,7 \pm 0,19$ \\
\hline C. sanguinea & $5,0 \pm 0,20$ & $1,41 \pm 0,03$ & $16,6 \pm 0,89$ & $3,2 \pm 0,16$ \\
\hline
\end{tabular}


Таким образом, изученные растения Crataegus отличаются разнородными морфометрическими параметрами. Наименьшие значения морфометрических показателей соцветий установлены для C. laevigata, наибольшие для C. maximoviczii и C. dahurica.

Фактор систематической принадлежности растения оказывает влияние на морфометрические характеристики соцветий. По данным однофакторного дисперсионного анализа, доля влияния показателя видовой принадлежности на число цветков в соцветии составляет $63 \%$, на ширину соцветий $-47 \%$, на диаметр цветков $-31 \%$, на плотность соцветия $-23 \%$. В условиях Кольской Субарктики в наибольшей степени от видовых особенностей зависит количество цветков в соцветии, другие изученные показатели испытывают меньшее влияние видовой принадлежности. Результаты данного анализа отличны от полученных исследователями в Республике Марий Эл [4; 5], что может свидетельствовать об особенностях интродукции данных видов боярышников в субарктических условиях.

Корреляционный анализ показал положительную зависимость между средними значениями количества цветков и плотностью соцветия $(\mathrm{r}=0,79$ при $\alpha=0,001)$. Наименее тесная корреляционная связь между данными показателями отмечена - у C. flabellata $(\mathrm{r}=0,63)$, наиболее тесная у C. dahurica $(\mathrm{r}=0,93)$. Таким образом, более плотное соцветие характерно для видов с большим количество цветков в соцветии.

Виды с малыми размерами цветков отличаются некрупными соцветиями, об этом свидетельствует слабая корреляционная связь между данными параметрами $(\mathrm{r}=0,32$ при $\alpha=0,001)$. Отсутствуют достоверные корреляционные связи между плотностью соцветия и размером цветков, между шириной соцветия и их плотностью и между размером цветков и их количеством.

\section{Заключение}

При оценке адаптации растений к новым экологическим условиям при интродукции существенную роль играет анализ характеристик цветения (продолжительность префлорального периода, цветения). В целом, фенологическое развитие изученных боярышников соответствует экологическим условиям Кольской Субарктики, растения проходят полный цикл развития, являются зимостойкими и жизнеспособными. Интродуцированные образцы рода Crataegus L. характеризуются ежегодным цветением. Наиболее декоративны во время цветения виды с более крупными цветками и соцветиями: C. maximoviczii и C. dahurica. Следовательно, наряду с C.dahurica, применяемым в зеленом строительстве городов Мурманской области, C. maximoviczii рекомендуется к использованию в озеленении заполярных городов.

\section{Список литературы:}

1. Семко А.П. Гидротермический режим почв лесной зоны Кольского полуострова. Апатиты: КФ AН СССР, 1982. $142 \mathrm{c}$.

2. Гончарова О.А. Состав коллекции интродуцированных древесных растений семейства Rosaceae Juss. в Полярно-альпийском ботаническом садуинституте // Биологическое разнообразие. Интродукция растений: мат-лы шестой междунар. науч. конф. 20-25 июня 2016 г., Санкт-Петербург. СПб.: ООО «СИНЭЛ», 2016. С. 107-109.
3. Полетико O.M. Боярышник - Crataegus L. // Деревья и кустарники СССР. Т. 3. М.-Л.: Изд-во АН CСCP, 1954. C. 514-577.

4. Мухаметова С.В., Григорьева К.Ю., Файзуллина Г.М. Декоративные качества соцветий и цветков боярышника // Субтропическое и декоративное садоводство: сб. науч. тр. Сочи: ГНУ ВНИИЦиСК Россельхозакадемии, 2013. Вып. 49. С. 122-127.

5. Мухаметова С.В., Кожина Н.А. Показатели соцветий боярышников секции Crataegus // Международный журнал гуманитарных и естественных наук. 2018. T. 1, № 5. C. 153-156.

6. Вафин Р.В., Путенихин В.П. Боярышники (интродукция и биологические особенности). М.: Наука, 2003. $224 \mathrm{c}$.

7. Скроцкая О.В., Мифтахова С.А. Некоторые виды семейства Rosaceae Juss.: интродукция и перспективы культивирования на севере // Вестник ИрГСХА. 2001. Вып. 44, июль. С. 122-130.

8. Петрик В.В., Александрова Ю.В., Васильева Н.Н. Фенологическое развитие некоторых видов боярышников в дендрологическом саду САФУ // Ландшафтная архитектура в ботанических садах и дендропарках: междунар. конф., 28 сентября - 2 октября 2016 г., Южно-Сахалинск: Типография «Транспорт», 2016. C. $120-124$.

9. Маслаков Н.И. Выращивание боярышника на Кольском Севере. Информационный листок. Мурманск: ЦНТИ. 2001.

10. Зотова О.Е., Гончарова О.А. Генеративное развитие некоторых видов рода Crataegus L. в условиях Кольской Субарктики // Растения в холодных регионах: сб. материалов всерос. науч.-практ. конф. Якутск, 20-21 октября 2016 г. Якутск: Издательский дом СВФУ, 2017. С. 78-82.

11. Гончарова О.А., Полоскова Е.Ю., Зотова О.Е., Липпонен И.Н. Некоторые вопросы интродукции образцов Crataegus L. на Кольском Севере // Самарский научный вестник. 2017. Т. 6, № 2 (19). С. 31-35.

12. Species in Crataegus [El. resource] // The Plant List. - http://theplantlist.org/1.1/browse/A/Rosaceae/Crataegus.

13. Черепанов С.К. Сосудистые растения России и сопредельных государств (в пределах бывшего СССР). Русское издание. СПб.: Мир, 1992. 992 с.

14. Методика фенологических наблюдений в ботанических садах СССР / М.С. Александрова, Н.Е. Булыгин, В.Н. Ворошилов и др. М.: Наука, 1975. 28 с.

15. Александрова Н.М., Головкин Б.Н. Переселение деревьев и кустарников на Крайний Север. Л.: Наука, 1978. 116 с.

16. Булыгин Н.Е. Дендрология. Фенологические наблюдения над лиственными древесными растениями. Л.: ЛТА, 1976. 70 с.

17. Зайцев Г.Н. Математика в экспериментальной ботанике. М.: Наука, 1990. 296 с.

18. Доспехов Б.А. Методика полевого опыта (с основами статистической обработки результатов исследований). 5-е изд., доп. и перераб. М.: Агропромиздат, $1985.351 \mathrm{c}$.

19. Ивантер Э.В., Коросов А.В. Введение в количественную биологию: учеб. пособие. Петрозаводск: ПетрГУ, 2003. 304 с.

20. Коросов А.В., Горбач В.В. Компьютерная обработка биологических данных: метод. пособие. Петрозаводск: Изд-во ПетрГУ, 2010. 84 с.

21. Лапин П.И. Сезонный ритм развития растений и его значение для интродукции // Бюллетень Главного ботанического сада. 1967. Вып. 65. С. 13-18. 


\section{MORPHOMETRIC CHARACTERISTICS OF INFLORESCENCES AND PHENOLOGY OF INTRODUCED PLANTS OF THE GENUS CRATAEGUS L. IN THE KOLA SUBARCTIC CONDITIONS}

(C) 2019

Zotova Olesya Evgenievna, junior researcher of Plant Introduction and Acclimatization Laboratory

Goncharova Oksana Aleksandrovna, candidate of biological sciences,

senior researcher of Plant Introduction and Acclimatization Laboratory

N.A. Avrorin Polar-Alpine Botanical Garden-Institute of Kola Scientific Centre of Russian Academy of Sciences

(Apatity, Murmansk Region, Russian Federation)

Abstract. This paper presents phenological development of seven introduced species of the genus Crataegus L. in the Kola North. The studied hawthorn species are characterized by early onset of vegetation, short duration of linear growth of shoots and a short vegetation period. Timely completion of growth processes and lignification of shoots contribute to successful adaptation of Crataegus plants under the conditions of introduction. The authors study morphometric parameters of flowers and inflorescences, decorative qualities, size and density of the inflorescence, the number of flowers in the inflorescence, the diameter of the flowers. The most decorative species of Crataegus during flowering are selected. The plants of the studied hawthorns are characterized by the average duration of the prefloral period, annual / irregular flowering. The most decorative species during flowering are the ones with larger flowers and inflorescences: C. maximoviczii and C. dahurica. Species with a large number of flowers are characterized by a denser inflorescence. Species with smaller flowers form smaller inflorescences and vice versa. In the conditions of the Kola Subarctic, the number of flowers in the inflorescence depends mainly on the specific features. C. maximoviczii is recommended for gardening in northern cities.

Keywords: ecological factors; ecological conditions; introduction; phenological development; phenological phases; duration of vegetation; woody plants; Rosaceae Juss. family - Rosaceous; genus Crataegus L. - hawthorn; prefloral period; duration of bloom; bloom; number of flowers; inflorescence; size of inflorescences; density of inflorescences; Kola Subarctic.

$* * *$

УДК $57.042 ; 577.3$

DOI 10.24411/2309-4370-2019-13107

Статья поступила в редакцию 10.06.2019

\section{ACER PLATANOIDES L. В УСЛОВИЯХ АНТРОПОГЕННОЙ НАГРУЗКИ Г. ДОНЕЦКА}

(C) 2019

Корниенко Владимир Олегович, старший преподаватель кафедры биофизики

Кольченко Ольга Руслановна, магистрант кафедры биофизики

Донецкий национальный университет (г. Донецк, Донецєкая Народная Республика)

Матвеева Татьяна Борисовна, кандидат биологических наук, доцент кафедры биологии, экологии и методики обучения

Самарский государственный соџиально-педагогический университет (г. Самара, Российская Федерация)

Аннотащия. В данной статье представлена не описанная ранее в условиях города Донецка экологобиологическая характеристика клена остролистного (Acer platanoides L.). Описывается городская среда как уроэкосистема и трансформации в ней под воздействием антропогенных факторов. Рассматривается влияние антропогенной среды в городе на растительные организмы, а также физиологические и морфологические изменения в них. В ходе проведенных исследований определен высокий уровень антропогенной нагрузки в городе Донецке на основе анализа показателей вибрационно-акустического шума вдоль автомагистралей, концентрации тяжелых металлов в почвах и концентрации аэрополлютантов в атмосферном воздухе на исследуемых участках. Установлена тесная связь показателя флуктуирующей асимметрии листовых пластин клена остролистного с показателем жизнеспособности и уровнем шумового загрязнения вдоль автомагистралей. Изучены основные параметры механической устойчивости Acer platanoides L. в г. Донецке в условиях техногенной нагрузки и в зоне контроля (дендрарий Донецкого ботанического сада). Установлено, что наибольшему риску облома подвержены молодые деревья (5-7 лет) и деревья, имеющие низкий балл жизнеспособности вследствие приближения критического возраста в условиях города. Полученные результаты могут быть использованы при биомониторинговых исследованиях состояния окружающей городской среды.

Ключевые слова: Acer platanoides L.; антропогенная нагрузка; тяжелые металлы; аэрополлютанты; вибрационно-акустический шум; механическая устойчивость; жесткость на изгиб; флуктуирующая асимметрия; жизнеспособность; город Донецк; Донецкий ботанический сад; биомониторинг; биоиндикация; городская среда; древесные растения.

\section{Введение}

Город на современном этапе - это природноантропогенная система, основными системообразующими факторами которой являются человек и природная среда $[1$, с. 9]. В этой системе имеется большое количество антропогенных фактов. Поэтому очень трудно выделить влияние одного фактора на живые организмы в отрыве от остальных. Городская среда активно аккумулирует и накапливает загрязняющие вещества и отходы, засоряя при этом атмосферу, водоемы и почвы [2, с. 129]. В центральных частях города часто отмечается превышение пре- 